\title{
Polycyclic Aromatic Hydrocarbons in Insular and Coastal Soils of the Russian Arctic
}

\author{
E. V. Abakumov ${ }^{a}$, V. M. Tomashunas ${ }^{a}$, E. D. Lodygin ${ }^{b}$, D. N. Gabov ${ }^{b}$, V. T. Sokolov ${ }^{c}$, \\ V. A. Krylenkov ${ }^{a}$, and I. Yu. Kirtsideli ${ }^{d}$ \\ ${ }^{a}$ St. Petersburg State University, 16 Liniya VO 29, St. Petersburg, 199178 Russia \\ ${ }^{b}$ Institute of Biology, Komi Scientific Center, Ural Branch, Russian Academy of Sciences, \\ ul. Kommunisticheskaya 28, Syktyvkar, 167982 Komi Republic, Russia \\ ${ }^{c}$ Arctic and Antarctic Research Institute, ul. Beringa 38, Saint Petersburg, 199397 Russia \\ ${ }^{d}$ Komarov Botanical Garden, Russian Academy of Sciences, ul. Prof. Popova 2, St. Petersburg, 197376 Russia \\ e-mail:e_abakumov@mail.ru \\ Received March 31, 2014
}

\begin{abstract}
The content and individual component compositions of polycyclic aromatic hydrocarbons in polar soils of the Russian Arctic sector have been studied. The contamination of soils near research stations is identified from the expansion of the range of individual polycyclic aromatic hydrocarbons, the abrupt increase in the content of heavy fractions, and the accumulation of benzo[ $a]$ pyrene. Along with heavy hydrocarbons, light hydrocarbons (which are not only natural compounds, but also components of organic pollutants) are also accumulated in the contaminated soils. Heavy polycyclic aromatic hydrocarbons are usually of technogenic origin and can serve as markers of anthropogenic impact in such areas as Cape Sterligov, Cape Chelyuskin, and the Izvestii TsIK Islands. The content of benzo[ $a$ ]pyrene, the most hazardous organic toxicant, appreciably increases in soils around the stations, especially compared to the control; however, the level of MPC is exceeded only for the soils of Cape Chelyuskin.
\end{abstract}

Keywords: Arctic soils, cryozems (Cryosols), soil-ecological status of landscapes

DOI: $10.1134 / \mathrm{S} 1064229315120029$

\section{INTRODUCTION}

The Arctic has become the subject of numerous studies on the content of persistent organic pollutants for assessing their chemical stability and ability to migrate to long distances. In addition, the data can be used in regular studies for assessing the basic trends in the accumulation of key pollutants in soil organic matter $[2,3,5]$. This is of special importance for the polar regions with immature soils, where landscapes relatively unaffected by anthropogenesis can be found [1, 2, 4, 14]. Polycyclic aromatic hydrocarbons (PAHs) from the low-latitude industrial regions of the Northern hemisphere can be transferred to long distances in the atmosphere and reach polar regions [22-25]. In the polar regions with low temperatures, PAHs are less subjected to microbial degradation; therefore, they are deposited and preserved in soils, easily introduced into fatenriched polar trophic chains, and accumulated in biota. The combination of the hard climatic conditions with the physicochemical properties of persistent toxic compounds makes the polar regions a zone of the final accumulation of these substances, which can result in an increase in their content compared to the source regions. The monitoring of this group of compounds may be used for the determination of the anthropogenic load on the Arctic.

PAHs are common organic pollutants accumulated in soils both due to the input of natural organic matter and from technogenic sources. The PAHs manifesting carcinogenic, mutagenic, and toxic properties for living organisms are included in the permanent monitoring list by the EU and US Environmental Protection Agency [23-28]. Benzo[a]pyrene is an organic toxicant of priority; its content is controlled by the Russian agencies regulating the quality of the environment: the maximum permissible concentration (MPC) of this compound for soils and sediments is $20 \mathrm{ng} / \mathrm{g}$ in Russia [9, 17].

Naphthalene, fluorene, phenanthrene, anthracene, fluoranthene, benzo[ $a]$ anthracene, and chrysene can be conventionally classified as light hydrocarbons; benzo[ $b]$ fluoranthene, benzo[ $k]$ fluoranthene, benzo $[a]$ pyrene, dibenzo $[a, h]$ anthracene, benzo $[g, h, i]$ perylene, and indeno $[1,2,3-c, d]$ pyrene can be classified as heavy hydrocarbons. In spite of the wide diversity of processes resulting in the formation of PAHs, the most common mechanism of their formation is the thermal impact on organic matter, as well as the biogeochemical transformation of the orig- 


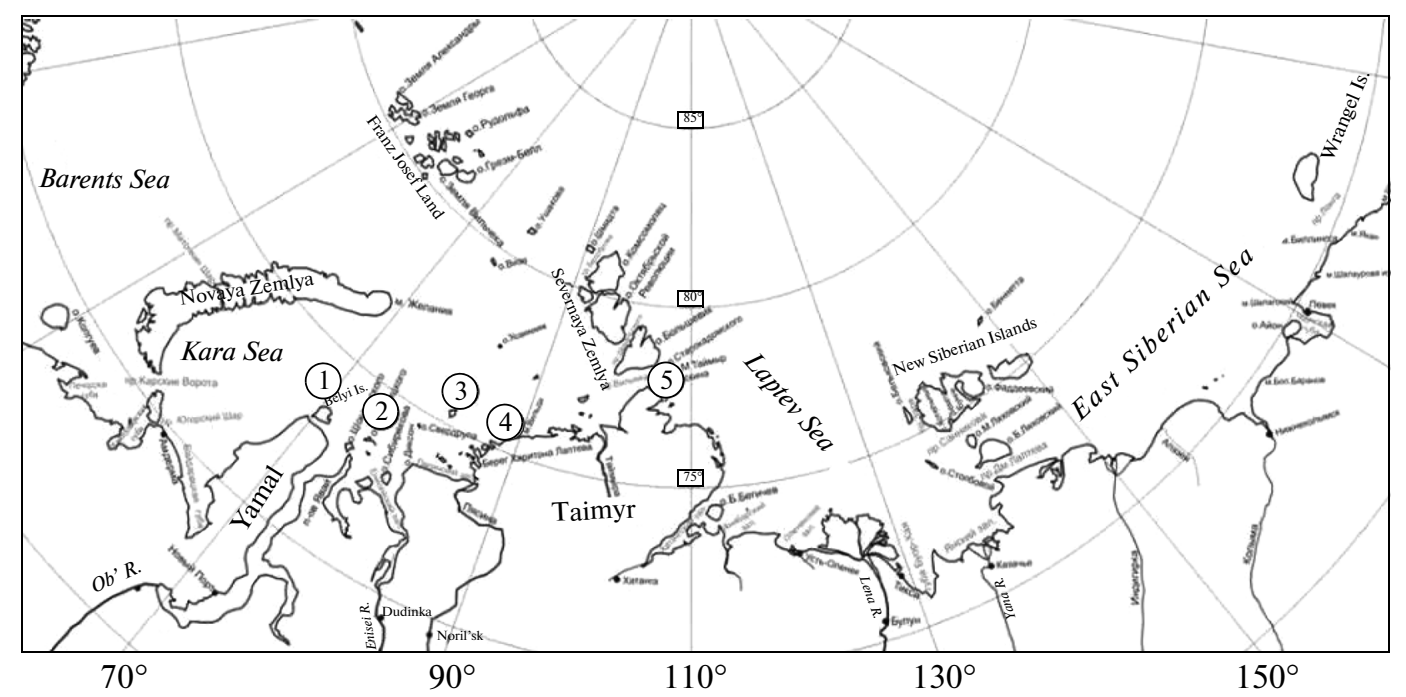

Fig. 1. Objects of study: (1) Island Belyi; (2) Island Vilkitsky; (3) Islands Izvestii TsIK; (4) Cape Sterligov; (5) Cape Chelyuskin.

inal biogenic material or the synthesis processes in organisms and bio-abiotic systems. The light PAHs are of natural or technogenic origin, depending on the specific object of study. The development of criteria for the discrimination between the natural and technogenic origin is a current task of PAH studies. The ratio between the natural and anthropogenic PAHs can be indicative of the degree of anthropogenic modification of soils, and some PAHs can be used as markers of some technogenic impacts on the biosphere [8].

Benzo $[a]$ pyrene is one of the key carcinogenic compounds formed during the incomplete combustion of hydrocarbon fuel and wood; it is also released from burning peat fields, abandoned coalmines, etc. It is believed that in the terrestrial ecosystems, benzo $[a]$ pyrene is mainly accumulated in soils $[11,18]$. The soil concentrations of benzo[ $a]$ pyrene are almost always directly related to the level of technogenic chemical impact on the environment [12, 13]. This compound rapidly dissipates and migrates in water and air; therefore, its concentration cannot be strongly related to the contamination levels. Various approaches for the regulation of benzo[a]pyrene content are used; the Russian criteria are among the severest [10-12]. The contamination of soils with this organic toxicant of priority is a critical problem in many settlements of Russia. The study of benzo[ $a]$ pyrene accumulation in the soils of regions under development is a specific, crucial task. Therefore, the aim of the current work was to study the presence and accumulation levels of benzo[ $[a]$ pyrene in soils and sediments of Russian polar stations. Diesel fuel is their major source of energy. A diesel power plant operates at each year-round station to warm the working and living spaces. The continuous operation of the power stations over tens of years should result in the accumulation of benzo $[a]$ pyrene in the natural environments, primarily soils. The study of this phenome- non is important not only for purely scientific purposes (soil chemistry, biogeochemistry, ecology), but also for the estimation of the sanitary-hygienic state of human habitats, as established by the Federal Law on sanitary and epidemiological welfare of population [19]. Insufficient information is available on the content and composition of PAHs in the soils of polar regions; there are only isolated data about PAHs in soils of the middle and northern taiga [6-8].

The aim of this work was to study the qualitative and quantitative composition of PAHs in soils of the Russian Arctic sector, including the determination of benzo[a]pyrene, an organic toxicant of priority, in soils.

\section{OBJECTS AND METHODS}

Soils and sediments for studying were sampled by Kirtsideli and Tomashunas in the course of the 135th and 137th high-latitude Arctic expeditions. Samples were taken in pairs, one from a natural landscape and one from an anthropogenically modified landscape. Three soil samples were taken from a depth of $0-10 \mathrm{~cm}$ on each plot; a total of 30 samples were analyzed. The soils sampled were cryozems (Cryosols) and lithozems (Leptosols): surface gleyic cryozems with a lightened texture on Island Belyi, strongly rubbly lithozems on Island Vilkitsky, heavy loamy cryozems of the Izvestii TsIK Islands, heavy loamy cryogenic gleyzems (or gleyic cryozems) on Cape Chelyuskin, and medium loamy gleyic cryozems on Cape Sterligov.

Anthropogenic impact is observed in the regions of the operating polar infrastructure; the "aftereffect" of the former stations and field bases is also possible. Anthropogenically almost unaffected natural landscapes accessible for high-latitude Arctic expeditions are usually located several kilometers from the present or former polar stations. The location of the objects of study in the Russian Arctic sector is shown in Fig. 1. 


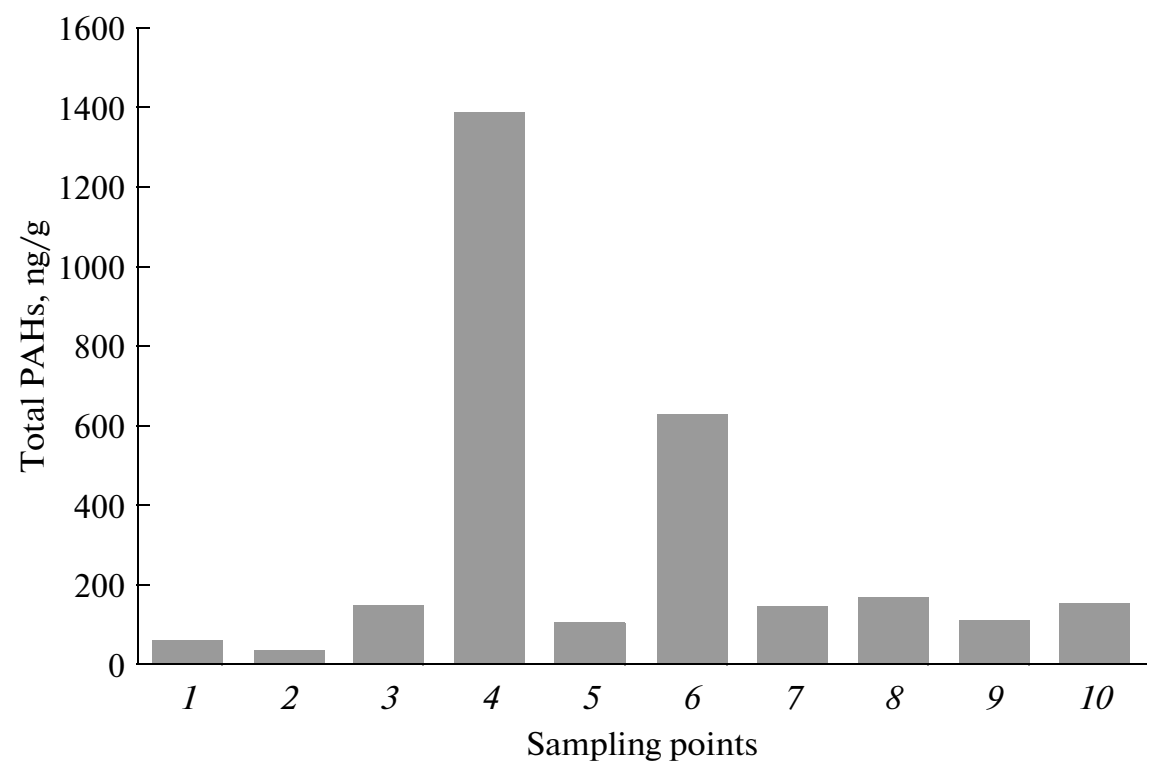

Fig. 2. Total PAHs in the sampling points (control and station plots, respectively): $(1,2)$ Island Vilkitsky; $(3,4)$ Islands Izvestii TsIK; $(5,6)$ Cape Chelyuskin; $(7,8)$ Island Belyi; $(9,10)$ Cape Sterligov.

In the soils and contaminated sediments of the Arctic, an integrated study of the qualitative and quantitative composition of 15 priority PAHs - naphthalene, acenaphthene, fluorene, anthracene, fluoranthene, pyrene, benzo[ $a]$ anthracene, chrysene, benzo[b]fluoranthene, benzo[k]fluoranthene, benzo[a]pyrene, dibenzo[ $a, h]$ anthracene, benzo $[g, h, i]$ perylene, and indeno[1,2,3-c,d]pyrene-was performed.

Before the extraction of PAHs, soil samples were triturated and passed through a 1-mm sieve to obtain fine earth, which was used for analytical procedures. The determination of PAHs were based on the described procedures [15, 16, 26-28], as well as an orig-

Table 1. PAHs and benzo[ $[a]$ pyrene in soils of the control plots (above the line) and the near-station areas (under the line), $\mathrm{ng} / \mathrm{g}$

\begin{tabular}{l|c|c|c}
\hline \multirow{2}{*}{\multicolumn{1}{c|}{ Object }} & Ben- & \multicolumn{2}{c}{ PAHs } \\
\cline { 3 - 4 } & zo[a]pyrene & heavy & light \\
\hline Vilkitsky I. & $\frac{0.7 \pm 0.3}{0.6 \pm 0.3}$ & $--^{*}$ & $\frac{60 \pm 30}{37 \pm 18}$ \\
Izvestii TsIK Is. & $\frac{-}{60 \pm 30}$ & $\frac{-}{260 \pm 80}$ & $\frac{150 \pm 50}{1100 \pm 400}$ \\
Cape Chelyuskin & $\frac{-}{29 \pm 14}$ & $\frac{-}{160 \pm 50}$ & $\frac{110 \pm 30}{460 \pm 150}$ \\
Belyi I. & $\frac{-}{8 \pm 4}$ & $\frac{-}{29 \pm 15}$ & $\frac{140 \pm 50}{140 \pm 40}$ \\
Cape Sterligov & $\frac{-}{3.1 \pm 1.6}$ & $\frac{-}{5.0 \pm 2.6}$ & $\frac{110 \pm 30}{150 \pm 50}$ \\
\hline
\end{tabular}

* Measurement result is below the lower determination limit. inal work [7]. The extraction was performed with a hexane-acetone $(1: 1)$ mixture at room temperature under ultrasonic treatment on a Branson 5510 sonicator according to the described procedure [26]. The PAH fraction was purified by column chromatography on silica gel [27]. The qualitative and quantitative determination of PAHs in soils was performed by reversed-phase high performance liquid chromatography in step gradient mode and spectrofluorimetric detection on a Lumachrom chromatograph (Lumex, Russia). Chromatography was operated at $30^{\circ} \mathrm{C}$ on a Supelcosil LCPAH column $(25 \mathrm{~cm} \times 2.1 \mathrm{~mm}, 5 \mu \mathrm{m}$ particles, Supelco) using an acetonitrile-water gradient. A sample of $10 \mu \mathrm{L}$ was introduced with a sampling valve. Individual PAHs were identified from the retention times and by comparing the fluorescence spectra of the components released from the column with the spectra of PAH standards. The quantification of PAHs was performed by the external standard method. To estimate the accuracy of the method, a standard reference material 1944 (New York/New Jersey waterway sediment) was treated using the above procedure, and a satisfactory result was obtained. The content of PAHs in soils was expressed in $\mathrm{ng} / \mathrm{g}$ fine earth. Statistical processing was performed using Sigmaplot software.

\section{RESULTS AND DISCUSSION}

The contents and proportions of PAHs in soils of the control plots and the key plots at the stations are given in Table 1 and Fig. 2. The contents of total PAHs in the soils of the stations were higher than in the soils of the control plots in all the cases, except for Island Vilkitsky. The differences observed between the samples from Island Vilkitsky are probably within the 
Table 2. PAH composition in Arctic soils (the contents in the control and near-station soils are given above and under the line, respectively), mean \pm standard deviation, $\mathrm{ng} / \mathrm{g}$

\begin{tabular}{|c|c|c|c|c|c|}
\hline PAH & Vilkitsky I. & Izvestii TsIK Is. & Cape Chelyuskin & Belyi I. & Cape Sterligov \\
\hline Naphthalene & $\frac{20 \pm 10}{-*}$ & $\frac{51 \pm 26}{120 \pm 60}$ & $\frac{-}{26 \pm 13}$ & $\frac{23 \pm 12}{29 \pm 14}$ & $\frac{33 \pm 17}{18 \pm 7}$ \\
\hline Fluorene & $\frac{3.3 \pm 1.3}{2.4 \pm 1.0}$ & $\frac{10 \pm 4}{36 \pm 14}$ & $\frac{-}{8 \pm 3}$ & $\frac{3.5 \pm 1.4}{6.5 \pm 2.6}$ & $\frac{7.0 \pm 2.8}{4.3 \pm 1.7}$ \\
\hline Phenanthrene & $\frac{22 \pm 11}{12 \pm 6}$ & $\frac{70 \pm 40}{280 \pm 60}$ & $\frac{3.8 \pm 1.9}{110 \pm 24}$ & $\frac{110 \pm 24}{60 \pm 30}$ & $\frac{50 \pm 25}{70 \pm 40}$ \\
\hline Anthracene & $\frac{1.0 \pm 0.5}{-}$ & $\frac{0.8 \pm 0.4}{19 \pm 4}$ & $\frac{-}{11 \pm 5}$ & $\frac{0.6 \pm 0.3}{1.3 \pm 0.7}$ & $\frac{0.9 \pm 0.5}{1.9 \pm 1.0}$ \\
\hline Fluoranthene & $\frac{5.8 \pm 2.6}{5.0 \pm 2.3}$ & $\frac{7 \pm 3}{250 \pm 100}$ & $\frac{-}{130 \pm 50}$ & $\frac{2.9 \pm 1.3}{3.1 \pm 1.4}$ & $\frac{3.2 \pm 1.5}{24 \pm 11}$ \\
\hline Pyrene & $\frac{3.0 \pm 1.0}{17 \pm 8}$ & $\frac{5.0 \pm 2.3}{280 \pm 100}$ & $\frac{-}{110 \pm 50}$ & $\frac{-}{17 \pm 8}$ & $\frac{8 \pm 4}{23 \pm 11}$ \\
\hline Benzo $[a]$ anthracene & $\frac{1.5 \pm 0.6}{0.30 \pm 0.14}$ & $\frac{-}{60 \pm 25}$ & $\frac{-}{30 \pm 13}$ & $\frac{-}{8 \pm 4}$ & $\frac{0.9 \pm 0.4}{2.6 \pm 1.1}$ \\
\hline Chrysene & $\frac{4.0 \pm 2.1}{1.4 \pm 0.7}$ & $\frac{3.1 \pm 1.6}{80 \pm 40}$ & $\frac{1.4 \pm 0.7}{40 \pm 21}$ & $\frac{3.0 \pm 1.6}{12 \pm 6}$ & $\frac{0.9 \pm 0.4}{6 \pm 3}$ \\
\hline Benzo $[b]$ fluoranthene & $=$ & $\frac{-}{80 \pm 30}$ & $\frac{-}{50 \pm 21}$ & $\frac{-}{10 \pm 4}$ & $\bar{z}$ \\
\hline Benzo $[k]$ fluoranthene & $\frac{0.50 \pm 0.24}{0.8 \pm 0.4}$ & $\frac{0.20 \pm 0.12}{36 \pm 17}$ & $\frac{-}{21 \pm 10}$ & $\frac{0.50 \pm 0.22}{3.9 \pm 1.9}$ & $\frac{0.5 \pm 0.2}{1.9 \pm 0.9}$ \\
\hline Benzo $[a]$ pyrene & $\frac{0.7 \pm 0.3}{0.6 \pm 0.3}$ & $\frac{-}{60 \pm 30}$ & $\frac{-}{29 \pm 14}$ & $\frac{-}{8 \pm 4}$ & $\frac{-}{3.1 \pm 1.6}$ \\
\hline Dibenzo $[a, h]$ anthracene & $\bar{z}$ & $\frac{-}{5.5 \pm 2.6}$ & $\frac{-}{7 \pm 4}$ & $\begin{array}{l}\bar{z} \\
=\end{array}$ & $\bar{z}$ \\
\hline Benzo $[g, h, i]$ perylene & $\bar{z}$ & $\frac{-}{45 \pm 20}$ & $\frac{-}{34 \pm 15}$ & $\frac{-}{8 \pm 3}$ & $\bar{z}$ \\
\hline Indeno $[1,2,3-c, d]$ pyrene & $\bar{z}$ & $\frac{-}{34 \pm 15}$ & $\frac{-}{24 \pm 11}$ & $\bar{z}$ & $\bar{z}$ \\
\hline
\end{tabular}

* Measurement result is below the lower determination limit.

determination error, which is confirmed by the insignificant differences in the contents of total heavy PAHs and benzo[ $a]$ pyrene.

The highest contents of PAHs are typical for the soils of the Izvestii TsIK Islands and the Chelyuskin polar station, where many PAHs and significant amounts of benzo[ $a]$ pyrene are accumulated in the soils around the station, which is related to the anthropogenic contamination of the environment. It is important that a high background content of PAHs with the minimum proportion of the heavy fraction is observed in the Izvestii TsIK Islands and at the Chelyuskin station, which indicates a significant contribution of light PAHs to the natural accumulation and transformation of organic matter. This does not contradict the accumulation of heavy PAHs, although the content of light PAHs in the contaminated soils is also high. Analogous tendencies in soil contamination are observed at the Chelyuskin station, where the content of heavy PAHs is high.

The data in Table 1 indicate that the highest contents of benzo $[a]$ pyrene are found in the contaminated soils from Cape Sterligov, the stations in the Belyi and Izvestii TsIK Islands, and the Chelyuskin station. The maximum content of this priority toxicant is typical for the soils of the Chelyuskin station, where the levels of MPC are exceeded.

The comparison of the contents of PAHs in the background soils and the soils occurring near the stations is shown in Table 2. The soils of the control plots strongly differ in the qualitative composition and content of PAHs. The light PAHs prevail there, while the heavy PAH fractions are accumulated in the soils near the stations. At the same time, the proportions of fluoranthene, pyrene, and benzo[a]pyrene in the light $\mathrm{PAH}$ fraction increase; although these are not light 
PAHs, they can partially accumulate under anthropogenic impact. The poorest qualitative composition of PAHs is observed in the soils of uncontaminated landscapes from Island Belyi and the Chelyuskin station. In the other samples, the composition of the light PAH fraction is variable, but naphthalene and phenanthrene are dominants.

Reliable differences in the content of PAHs between the paired samples from the uncontaminated landscapes and the station soils are observed for the Izvestii TsIK Islands and the Chelyuskin and Sterligov stations. The highest diversity of PAHs accumulating in the contaminated soils is typical for the areas of the Izvestii TsIK Islands, the Chelyuskin station, and Island Belyi; the contents of the accumulated substances in these soils are different.

The organic toxicants of priority in Arctic soils are still poorly understood, which is related to the general insufficient study of soils in this macroregion and the apparent absence of potential contamination sources of polar soils. Therefore, the described attempt to study the individual composition and total content of PAHs is not completed; it rather points to the necessity of further investigations, which should include the increase in the range of the studied regions and the extension of the studied areas around the stations

\section{CONCLUSIONS}

The performed studies showed that PAHs are present in Arctic soils as an individual fraction of soil organic matter. Their environmental significance is related to ecological processes (deterioration of the sanitary quality of the environment) rather than to their amounts (their content is very low compared to the soil organic matter).

The contamination of soils near the stations is identified from the expansion of the range of individual PAHs, the abrupt increase in the content of heavy PAHs, and the accumulation of benzo[ $a]$ pyrene. Along with the accumulation of heavy PAHs, the content of light PAHs (which are components of not only natural substances, but also organic toxicants) in the contaminated soils also increases. The heavy PAHs are obviously of technogenic origin and can serve as markers of anthropogenic impact in such areas as Cape Sterligov, the Chelyuskin station, and the Izvestii TsIK Islands.

The content of benzo[ $a]$ pyrene, the most hazardous organic toxicant of priority, significantly increases in the soils around the stations, especially compared to the control; however, the MPC level is exceeded only in the soil of the Chelyuskin station.

\section{ACKNOWLEDGMENTS}

This work was supported in part by the Russian Foundation for Basic Research (project nos. 12-0400680-a, 14-04-31303 mol_a), the Ural Branch of the Russian Academy of Sciences (project no. 12-U-4-
1003), the St. Petersburg State University (project no. 1.37.151.2014), and the Grant of the President of the Russian Federation for young doctors in sciences (project no. MD 3615.2015.4).

\section{REFERENCES}

1. E. V. Abakumov, "Particle-size distribution in soils of West Antarctica," Eurasian Soil Sci. 43 (3), 297-304 (2010).

2. E. V. Abakumov, "The sources and composition of humus in some soils of West Antarctica," Eurasian Soil Sci. 43 (5), 499-508 (2010).

3. E. V. Abakumov, E. D. Lodygin, D. N. Gabov, and V. A. Krylenkov, "Polycyclic aromatic hydrocarbons in soils of Antarctica by example of Russian Polar stations," Gig. Sanit., No. 1, 30-34 (2014).

4. E. V. Abakumov, E. I. Gagarina, V. F. Sapega, and D. Yu. Vlasov, "Micromorphological features of the fine earth and skeletal fractions of soils of West Antarctica in the areas of Russian Antarctic stations," Eurasian Soil Sci. 46 (12), 1219-1229 (2013). doi 10.1134/S1064229313120028

5. D. Yu. Vlasov, E. V. Abakumov, M. A. Nadporozhskaya, N. V. Kovsh, V. A. Krylenkov, V. V. Lukin, and E. V. Safronova, "Lithosols of King George Island, western Antarctica," Eurasian Soil Sci. 38 (7), 681687 (2005).

6. D. N. Gabov, V. A. Beznosikov, B. M. Kondratenok, and E. V. Yakovleva, "Formation of polycyclic aromatic hydrocarbons in northern and middle taiga soils," Eurasian Soil Sci. 41 (11), 1180-11883 (2008).

7. D. N. Gabov, V. A. Beznosikov, and B. M. Kondratenok, "Polycyclic aromatic hydrocarbons in background podzolic and gleyic peat-podzolic soils," Eurasian Soil Sci. 40 (3), 256-264 (2007).

8. A. N. Gennadiev, Yu. I. Pikovskii, V. N. Florovskaya, T. A. Alekseeva, I. S. Kozin, A. I. Ogloblina, M. E. Ramenskaya, T. A. Teplitskaya, and E. I. Shurubor, Geochemistry of Polycyclic Aromatic Hydrocarbons in Rocks and Soils (Moscow State University, Moscow, 1996) [in Russian].

9. GN (State Normative) 2.1.7.2041-06: Maximum Permissible Concentrations of Chemical Elements in Soil, 2006.

10. D. A. Golubev and N. D. Sorokin, Environmental Protection, Nature Management, and Environmental Safety in St. Petersburg in 2002 (Sezam, St. Petersburg, 2003) [in Russian].

11. L. P. Kapel'kina, "Environmental aspects of pollution of urban soils: standardization paradoxes," Probl. Ozeleneniya Gorodov, No. 10, 191-195 (2004).

12. L. P. Kapel'kina, "Standardization of concentration of pollutants in urban soils of megapolis, in Proceedings of the Interregional Scientific-Practical Conference "Soil Resources of the Northwestern Russia: Status, Protection, and Rational Use" (St. Petersburg State Technological University, St. Petersburg, 2008), pp. 21-28.

13. E. D. Lodygin, V. A. Beznosikov, D. N. Gabov, and S. N. Chukov, "Polycyclic aromatic hydrocarbons in soils of Vasilievsky Island (St. Petersburg)," Eurasian Soil Sci. 41 (12), 1321-1326 (2008). 
14. A. V. Lupachev and E. V. Abakumov "Soils of Marie Byrd Land, West Antarctica," Eurasian Soil Sci. 46 (10), 994-1006 (2013). doi: 10.1134/S1064229313100049

15. PND F (Normative Document) 16.1:2:2.2:3.39-03: Quantitative chemical analysis of soils. A method of measurements of mass fractions of benzo[a]pyrene in samples of soils, grounds, solid wastes, bottom sediments by high performance liquid chromatography using Lyumakhrom chromatograph, 2007.

16. PND F (Normative Document) 16.1:2.2:2.3:3.62-09: Quantitative chemical analysis of soils. A method for measuring of the mass fractions of polycyclic aromatic hydrocarbons in soils, bottom sediments, sediments of waste waters, and industrial wastes by high performance liquid chromatography, 2009.

17. SanPiN (Sanitary Rules and Normatives) 42-1284433-87: Sanitary norms of permissible concentrations of chemicals in soil, 1987.

18. Sedykh, V.N., Paradoxes in Solution of Environmental Problems of Western Siberia (Nauka, Novosibirsk, 2005) [in Russian].

19. Federal Law of March 30, 1999, No. 52-FZ "About sanitary epidemiological safety of population," Edition of November 25, 2013, 1999.

20. E. V. Yakovleva, V. A. Beznosikov, B. M. Kondratenok, and D. N. Gabov, "'Bioaccumulation of polycyclic aromatic hydrocarbons in the soil-plant systems of the northern taiga biocenoses," Eurasian Soil Sci. 45 (3), 309-320 (2012). doi: 10.1134/S1064229312030143

21. E. Abakumov, O. Trubetskoj, D. Demin, L. Celi, C. Cerli, and O. Trubetskaya, "Humic acid characteristics in podzol soil chronosequence," Chem. Ecol. 26, 59-66 (2010).
22. P. Fernandez, J. O. Grimalt, and R. M. Vilanova, "Atmospheric gas/particle partitioning of polycyclic aromatic hydrocarbons in high mountain regions of Europe," Environ. Sci. Technol. 36, 1162-1168 (2002).

23. IARC (International Agency for Research on Cancer), "IARC monographs on the evaluation of the carcinogenic risk of chemicals to humans," in Polynuclear Aromatic Compounds. Part I. Chemical, Environmental, and Experimental Data (Lyon, France, 1983), Vol. 32.

24. R. W. Macdonald, L. A. Barrie, T. F. Bidleman, M. L. Diamond, D. J. Gregor, R. G. Semkin, W. M. Strachan, Y. F. Li, F. Wania, M. Alaee, L. B. Alexeeva, S. M. Backusand, R. Bailey, J. M. Bewers, C. Gobeil, et al., "Contaminants in the Canadian Arctic: 5 years of progress in understanding sources, occurrence and pathways," Sci. Total Environ. 254, 193-234 (2000).

25. U.S. Environmental Protection Agency, Evaluation and Estimation of Potential Carcinogenic Risks of Polynuclear Aromatic Hydrocarbons (Carcinogen Assessment Group, Office of Health and Environmental Assessment, Washington DC, 1985).

26. U.S. Environmental Protection Agency, Method 3550b: Ultrasonic Extraction, Revision 2 (Washington DC, 1996).

27. U.S. Environmental Protection Agency, Method 3630c: Silica Gel Cleanup, Revision 3 (Washington DC, 1996).

28. U.S. Environmental Protection Agency, Method 8310: Polynuclear Aromatic Hydrocarbons (Washington DC, 1986).

Translated by K. Pankratova 